\title{
The level of ascorbate peroxidase is enhanced in benznidazole-resistant populations of Trypanosoma cruzi and its expression is modulated by stress generated by hydrogen peroxide
}

\author{
Fernanda Barbosa Nogueira, Joyce Fernanda A Rodrigues, Marcos Messias S Correa, \\ Jerônimo Conceição Ruiz, Alvaro José Romanha, Silvane Maria Fonseca Murta/ ${ }^{+}$ \\ Laboratório de Parasitologia Celular e Molecular, Instituto René Rachou-Fiocruz, \\ Av. Augusto de Lima 1715, 30190-002 Belo Horizonte, MG, Brasil
}

\begin{abstract}
Ascorbate peroxidases (APX) are class I heme-containing enzymes that convert hydrogen peroxide into water molecules. The gene encoding APX has been characterized in 11 strains of Trypanosoma cruzi that are sensitive or resistant to benznidazole (BZ). Bioinformatic analysis revealed the presence of two complete copies of the T. cruzi $A P X(T c A P X)$ gene in the genome of the parasite, while karyotype analysis showed that the gene was present in the 2.000-kb chromosome of all of the strains analyzed. The sequence of TcAPX exhibited greater levels of similarity to those of orthologous enzymes from Leishmania spp than to APXs from the higher plant Arabidopsis thaliana. Northern blot and real-time reverse transcriptase polymerase chain reaction (RT-PCR) analyses revealed no significant differences in TcAPX mRNA levels between the T. cruzi strains analyzed. On the other hand, Western blots showed that the expression levels of TcAPX protein were, respectively, two and three-fold higher in T. cruzi populations with in vitro induced (17 LER) and in vivo selected (BZR) resistance to BZ, in comparison with their corresponding susceptible counterparts. Moreover, the two BZ-resistant populations exhibited higher tolerances to exogenous hydrogen peroxide than their susceptible counterparts and showed TcAPX levels that increased in a dose-dependent manner following exposure to 100 and $200 \mu M$ hydrogen peroxide.
\end{abstract}

Key words: Trypanosoma cruzi - drug resistance - ascorbate peroxidase - hydrogen peroxide

Chagas disease is a potentially life-threatening zoonosis whose etiological agent is the flagellate protozoan Trypanosoma cruzi. It is estimated that eight11 million people in Latin America are infected with the parasite (CDC 2007, Stuart et al. 2008), while 100 million living in endemic areas of the region (i.e., $25 \%$ of the total population of Latin America) are at risk of contracting the infection (Massad 2008). No vaccine is available for Chagas disease and, currently, only two drugs have been demonstrated to be efficacious against the illness in human trials, namely, nifurtimox (NFX) (4-(5-nitrofurfurylidenamino)-3-methylthiomorpholine-1,1-dioxide) and benznidazole (BZ) (N-benzyl-2nitro-1-imidazolacetamide). Although these drugs have been in use for more than 40 years, they both suffer from a number of drawbacks, including low cure rates in the chronic stage of the disease, significant toxic side effects and the existence of naturally resistant strains of T. cruzi (Urbina \& Docampo 2003). As a consequence of these problems, new drugs and novel targets for drug development are urgently required.

Financial support: CNPq, FAPEMIG, PDTIS/FIOCRUZ, CAPES

SMFM and AJR are CNPq fellowship recipients.

+ Corresponding author: silvane@cpqrr.fiocruz.br

Received 10 September 2011

Accepted 14 December 2011
The mechanisms of action of BZ and NFX are not entirely clear. BZ reportedly acts via reductive stress involving covalent modification of macromolecules, such as DNA and proteins and lipids (Docampo 1990). In addition, BZ and its metabolites can affect the trypanothione $\left[\mathrm{T}(\mathrm{SH})_{2}\right.$ ] metabolism of $T$. cruzi (Maya et al. 1997). The mode of action of NFX appears to involve the generation of reactive nitro-anion radicals that may either cause damage to the DNA of the parasite or lead to the production of superoxide anions and hydrogen peroxide (Docampo \& Moreno 1984). Recent studies suggest that both BZ and NFX are pro-drugs that are activated by nitroreductases (NTRs) to produce nitrogenated radicals (Wilkinson et al. 2008). Interestingly, the deletion of copies of genes encoding two different NTRs, namely, old yellow enzyme (TcOYE) (also named prostaglandin synthase) (Murta et al. 2006) and trypanosomal type I NTR (Wilkinson et al. 2008), has been associated with resistance of T. cruzi to NFX and BZ in vitro. While the mechanism of drug resistance in this parasite remains poorly understood, differences in susceptibility to BZ and NFX between T. cruzi strains (Filardi \& Brener 1987, Murta et al. 1998, Toledo et al. 2004) and/or the genetic diversity of the host (Filardi \& Brener 1987) may explain variations in the efficacies of the drugs.

During infection, $T$. cruzi invades various different cell types in the host and, in turn, is exposed to reactive oxygen species (ROS) produced by the processes of cellular respiration and by external agents, including products of the immune response of the host and of drug metabolism (Irigoín 2008). Since ROS can damage various 
cellular components, including membrane lipids, nucleic acids and proteins, all organisms possess defence mechanisms based on antioxidant enzymes (Piñeyro et al. 2005). However, trypanosomatid cells lack the enzymes catalase and selenium-dependent glutathione peroxidase that are capable of rapidly metabolising high levels of hydrogen peroxide (Flohé et al. 1999) and, in this respect, they are more sensitive to some forms of ROS than are vertebrate cells. Instead, kinetoplastids have a unique antioxidant defence system against hydroperoxides based on the lowmolecular-weight thiol, T(SH) ${ }_{2}$ (Nogoceke et al. 1997, Krauth-Siegel et al. 2003, Turrens 2004, Irigoín 2008). $\mathrm{T}(\mathrm{SH})_{2}$ directly reduces tryparedoxin, dehydroascorbate and glutathione disulphide by sequential reactions that are coupled with the reductive detoxification of peroxides and the formation of deoxyribonucleotides. The trypanothione disulphide $\left(\mathrm{TS}_{2}\right)$ so formed is reduced by nicotinamide adenine dinucleotide phosphate to $\mathrm{T}(\mathrm{SH})_{2}$ in a reaction catalysed by $\mathrm{T}(\mathrm{SH})_{2}$ reductase.

Ascorbate peroxidases (APXs) are class I heme-containing enzymes that catalyse the hydrogen-peroxidedependent oxidation of ascorbate in photosynthetic organisms (Raven 2003). It has been shown previously that extracts of T. cruzi exhibit ascorbate-dependent peroxidase activity (Docampo et al. 1976, Boveris et al. 1980, Clark et al. 1994) and Wilkinson et al. (2002) have characterised an ascorbate-dependent hemoperoxidase (TcAPX) in the parasite, the activity of which was associated with the $\mathrm{T}(\mathrm{SH})_{2}$ system. Interestingly, the amino acid sequence of TcAPX showed $30-35 \%$ similarity to plant APXs. The T. cruzi peroxidase is located in the endoplasmic reticulum and forms part of the antioxidant defence of the parasite by metabolising hydrogen peroxide to water. Since APX is absent in the human host, this enzyme must be considered a potential target for chemotherapy against Chagas disease (Wilkinson et al. 2002, Turrens 2004).

Recently, our group has shown that tryparedoxin peroxidase, which also participates in the antioxidant defence mechanism of T. cruzi, is over-expressed in populations of the parasite with in vitro induced resistance to BZ (Nogueira et al. 2009). Thus, the aims of the present study were to characterise APX in 11 strains of T. cruzi that were either susceptible or naturally resistant to BZ and NFX or had in vivo selected or in vitro induced resistance to $\mathrm{BZ}$ and to establish the copy number and chromosomal location of the TcAPX gene, the levels of TcAPX mRNA and of TcAPX protein expression and the phylogenetic relationship of TcAPX with APXs from other organisms. The levels of protein expression of TcAPX protein in T. cruzi populations that had been exposed to hydrogen peroxide were also investigated.

\section{MATERIALS AND METHODS}

Strains of T. cruzi - The BZ-resistant T. cruzi population (BZR) (17 LER) derived from the Tehuantepec cl2 susceptible-wild-type strain (17 WTS) (Nirdé et al. 1995) was obtained by in vitro exposure to increasing concentrations of BZ (LAFEPE Pharmaceutical Laboratory of the state of Pernambuco, Vitória de Santo Antão, Brazil). Parasites of the 17 LER population are resistant to $220 \mu \mathrm{M} \mathrm{BZ}$, a concentration that is 23 -fold higher than the inhibitory concentration (IC) $)_{50}$ of the 17 WTS control population. The BZR was derived from the susceptible $\mathrm{Y}$ strain (BZS) following in vivo selection after 25 successive passages in mice treated with a single high dose $(500 \mathrm{mg} / \mathrm{kg}$ body weight) of BZ (Murta \& Romanha 1998). The remaining seven strains of $T$. cruzi had been characterised previously according to their in vivo susceptibility to BZ and NFX (Filardi \& Brener 1987). The strains Colombiana, Noel and VL-10 are naturally resistant to both drugs, while CL Brener, Quaraizinho, Ernane and Luna are susceptible (Murta et al. 1998). All 11 strains were classified as T. cruzi group TcI, TcII or TcVI according to the newly published revised nomenclature for T. cruzi (Zingales et al. 2009). Epimastigote forms of all $T$. cruzi strains were grown in liver infusion tryptose (LIT) medium, washed in PBS and the parasite pellets were used for DNA, RNA and protein preparations.

In silico and phylogenetic analyses of the TcAPX gene - In silico analyses were conducted on a local server using in-house copies of the appropriate databases and software. Initially, the published sequence of TcAPX (GenBank accession AJ457987) (Wilkinson et al. 2002) was used to scan the locally compiled T. cruzi database (El-Sayed et al. 2005) for contigs presenting similarities to the query sequences using the Basic Local Alignment Search Tool (BLAST) (National Center for Biotechnology Information). BLAST hits that presented a minimum identity of $90 \%$ over a 100 -nucleotide stretch were selected for further manual annotation and two potential contigs (AAHK01002212 and AAHK01001145) were identified. Annotation and graphical output of the contigs was performed using ARTEMIS software (sanger.ac.uk/resources/software/artemis/) and in-house developed Practical Extraction and Report Language scripts to analyse and format the results. On the basis of published nucleotide (GenBank accessions AJ457987 and XM_799789) and amino acid (GenBank accessions CAD30023 and XP 804882) sequences relating to APX from T. cruzi, orthologous genes were identified in Leishmania major (GenBank accession CAJ07706.1), Leishmnia infantum (GenBank accession CAM71478.1) and Leishmania braziliensis (GenBank accession CAM38361.1). Additionally, the amino acid sequences for APXs from Arabidopsis thaliana (GenBank accessions CAA67425.1, CAA67426.1, Q05431 and CAA66640.1) were employed. The amino acid sequence of myeloperoxidase from Homo sapiens (GenBank accession NP000241.1) was used as an out-group since the APX enzyme is absent in humans. Selected sequences were compared using BLAST and WUBLAST (The Institute of Genomic Research) software. Both nucleotide (BLASTX) and amino acid (BLASTP) sequences of $T$. cruzi APX were compared with nonredundant sequences of proteins deposited in GenBank and the Leishmania database at GeneDB (genedb.org). The sequences obtained were aligned using CLUSTALW Windows interface (Thompson et al. 1997) and a phylogenetic tree was constructed with the aid of MEGA 3 software (Kumar et al. 2004).

Extraction of RNA and DNA - Total RNA and genomic DNA were extracted from T. cruzi populations using a previously described method (Nogueira et al. 
2006). Northern blots were carried according to the protocols described by Murta et al. (2006).

Real-time reverse transcriptase-polymerase chain reaction (RT-PCR) - The protocol employed for the preparation of first-strand cDNA and the procedure for realtime RT-PCR were as previously described (Nogueira et al. 2006). An ABI Prism 7000 - Sequence Detection System (SDS) (PE Applied Biosystems, Foster City, CA, USA) was employed in the real-time PCR amplification of first-strand cDNA $(5 \mu \mathrm{L})$ using the specific primers, 5'GCCACCGTGGCCTTATGTTAT'3 (RT TcAPX 1 forward) and 5' CATCGAAGCGGAATTAGGACTC3' (RT TcAPX 2 reverse), designed from the complete nucleotide sequence of TcAPX (GenBank accession AJ457987). According to the method of Nogueira et al. (2006), the T. cruzi housekeeping gene hypoxanthineguanine phosphoribosyltransferase (TcHGPRT) was used to normalise the amount of sample. PCR products were quantified using SDS data analysis software and normalised to the TcHGPRT values for each sample.

Pulsed-field gel electrophoresis (PFGE) - Agarose blocks containing intact $T$. cruzi chromosomes were prepared according to the method of Nogueira et al. (2006) and submitted to PFGE on an Amersham Pharmacia (GE Life Sciences, Little Chalfont, UK) Gene Navigator TM system. The best separations for TcAPX were obtained at $90 \mathrm{~V}$ and $9^{\circ} \mathrm{C}$ employing 250 -s pulses for $24 \mathrm{~h}, 500$-s pulses for $24 \mathrm{~h}, 750$-s pulses for $24 \mathrm{~h}$ and 1,000 -s pulses for $24 \mathrm{~h}$. The gels were transferred onto Hybond nylon membranes (GE Life Sciences) according to the manufacturer's instructions and the membranes were hybridised with a ${ }^{32} \mathrm{P}$-labeled TcAPX probe according to the protocol of Murta et al. (2006).

Cloning of the TcAPX gene - A 987-bp segment corresponding to the open reading frame of TcAPX (GenBank accession AJ457987) was amplified using the primers 5'cgcggatccccATGGCTTTTTGTTTTGGTTC-3' (TcAPX pGEX1 forward) and 5'-ccggaattcCTATTTTGACTCTGCTGGGA-3' (TcAPX pGEX2 reverse), containing sequences (shown in lower-case italic font) corresponding to BamHI and EcoRI restriction sites, respectively, to facilitate cloning. The PCR product encoding TcAPX was restricted with $B a m \mathrm{HI}$ and EcoRI and inserted into the corresponding sites of the pGEX-5X-3 expression vector (GE Life Sciences) containing a glutathione S-transferase (GST) gene from Schistosoma japonicum.

Purification of recombinant TcAPX protein and production of polyclonal antiserum - Cells of Escherichia coli strain BL21 were transformed with the expression vector carrying the PCR product, cultured for $4 \mathrm{~h}$ in the presence of $1 \mathrm{mM}$ isopropyl- $\beta$-D-thiogalactopyranoside (Promega, Madison, WI, USA), harvested and lysed. The GST-TcAPX recombinant protein (rTcAPX) so produced was separated on a glutathione Sepharose 4B column (GE Life Sciences) and purified using a Bio-Rad (Hercules, CA, USA) model 422 Electro-Eluter according to the procedure recommended by the manufacturer. Polyclonal antiserum was produced using a previously described protocol (Murta et al. 2006).
Western blot analysis - The expression levels of TcAPX were determined by Western blot analysis using rabbit anti-rTcAPX antiserum (diluted 1:500) and rabbit anti-heat shock protein of $70 \mathrm{kDa}$ (TcHSP70) antiserum (diluted 1:10,000) as control (Murta et al. 2008). The secondary antibody was peroxidase-linked anti-rabbit IgG (GE Life Sciences) used at a dilution of 1:6,000 and membranes were revealed with the aid of a GE Life Sciences chemiluminescence kit used according to the manufacturer's instructions.

Inhibition of T. cruzi populations by hydrogen peroxide - The half-maximal concentrations of hydrogen peroxide required to inhibit the growth $\left(\mathrm{IC}_{50}\right)$ of $\mathrm{BZS}$ and 17 WTS and BZR and 17 LER populations of T. cruzi were determined using a standard method. Log phase epimastigotes $\left(5 \times 10^{5}\right.$ cells in $1 \mathrm{~mL}$ LIT medium) were cultured in 24-well plates in the presence of different concentrations of hydrogen peroxide The percentages of live parasites were determined using a model Z1 Coulter Counter (Beckman Coulter, Fullerton, CA, USA) after three days in culture. $\mathrm{IC}_{50}$ values were determined from three independent measurements, each performed in triplicate.

Analysis of T. cruzi populations after treatment with hydrogen peroxide - Aliquots $(10 \mathrm{~mL})$ of epimastigotes ( $10^{7}$ cells $/ \mathrm{mL}$ ) of the T. cruzi populations $17 \mathrm{WTS}, 17$ LER, BZS and BZR were centrifuged and resuspended in incubation buffer (IB) (10 mL) (Carnieri et al. 1993). The parasites were incubated at room temperature for $1 \mathrm{~h}$ in the presence of $0,50,100$ or $200 \mu \mathrm{M}$ hydrogen peroxide, harvested, washed in IB buffer and collected by centrifugation at $4^{\circ} \mathrm{C}$ for $10 \mathrm{~min}$ at $1,500 \mathrm{~g}$. Protein were extracted from the parasite pellets according to the protocol of Garg et al. (2003) and aliquots $(20 \mu \mathrm{g})$ were separated by electrophoresis on $12 \%$ sodium dodecyl sulfate - polyacrylamide gels and subsequently transferred onto nitrocellulose membranes (Bio-Rad). Western blots were performed as described above.

Densitometric analysis - Northern autoradiograms and Western blot membranes were photographed and subsequently analysed using ImageMaster VDS software (GE Life Sciences). Differences were considered significant when the intensity band ratios were $\geq 2.0$.

\section{RESULTS}

In silico and phylogenetic analysis of TcAPX gene - A search of TcAPX (GenBank accession AJ457987) against a local copy of the T. cruzi database for sequence similarity revealed three protein-coding sequences associated with the $A P X$ gene function. Two of them represented full copy genes (GenBank accessions CAD30023 and XP 804882) and the third was a pseudogene (GenBank accession 3537790). Manual annotation of the contigs AAHK01001145 and AAHK01002212 was carried out using the ARTEMIS annotation tool. TcAPX sequences containing complete copies with correct annotation are provided in the Supplementary data. The global sequence alignment revealed high sequence similarity (98\%) with only four substitutions, namely, valine for alanine (V/A), phenylalanine for serine $(\mathrm{F} / \mathrm{S})$, glutamine for arginine $(\mathrm{Q} / \mathrm{R})$ and asparagine for aspartate (N/D) (Supplemen- 
tary data). The sequence for TcAPX (GenBank accession AJ457987), which encodes a protein comprising 328 amino acids with a predicted mass of $33 \mathrm{kDa}$, was subsequently employed in the remainder of the study.

The TcAPX sequence showed $57 \%$ similarity with orthologs from three Leishmania species and 25\% similarity with APXs from $A$. thaliana. Comparative analysis between the TcAPX sequence and database sequences from other species of trypanosomatids, including Trypanosoma brucei and Crithidia fasciculata, revealed that proteins similar to TcAPX have not been identified in these organisms.

In order to compare the amino acid sequence of TcAPX with APX sequences of different organisms, a neighbour-joining phylogenetic tree was constructed (Fig. 1). According to the bootstrap method, in which the assessment of confidence for each clade of an observed tree is based on the proportion of bootstrap trees showing that same clade (Efron et al. 1996), a high confidence level (bootstrap value of 100) was observed for APX sequences within the trypanosomatids and for the various APX sequences of $A$. thaliana. Interestingly, the phylogenetic tree revealed a clear divergence between trypanosomal and plant APX sequences, representing a dichotomous branching.

Chromosomal location of the TcAPX gene - Profiles comprising heterogeneous bands (ranging from 745$2,500 \mathrm{~kb}$ ) were obtained following PFGE separation of the chromosomes of different T. cruzi strains (Fig. 2A). Southern blot analysis of these chromosomes with a TcAPX-specific probe revealed that the gene was present in a chromosomal band of approximately $2,000 \mathrm{~kb}$ in all $T$. cruzi populations analysed (Fig. 2B). No correlation was observed between the chromosomal location of TcAPX and the drug-resistance phenotype.

Levels of TcAPX mRNA in T. cruzi populations Northern blot and real-time RT-PCR analyses were carried out in order to investigate the levels of TcAPX mRNA in $T$. cruzi populations. Fig. 3A displays the results obtained following hybridisation of the blots with a ${ }^{32} \mathrm{P}$-labelled TcAPX-specific probe and reveals the presence of two transcripts, one of $2.6 \mathrm{~kb}$ and another of

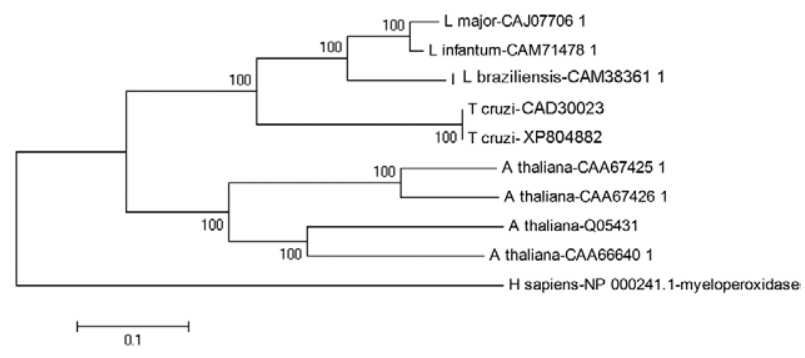

Fig. 1: neighbour-joining phylogenetic tree based on sequences of ascorbate peroxidase of Trypanosoma cruzi and other organisms with a high degree of similarity. In the consensus bootstrap tree (1,000 replicates), the numbers above each branch represent the bootstrap confidence percentage and the bar corresponds to a 0.1 nucleotide substitution. The amino acid sequence of the heme-dependent peroxidase, myeloperoxidase from Homo sapiens was employed as an out-group.
$3.3 \mathrm{~kb}$, in all populations of $T$. cruzi analysed. The transcript of $3.3 \mathrm{~Kb}$ presents higher expression level in both 17 WTS and 17 LER populations than the other samples analysed, however, no association with $T$. cruzi group was observed. Based on quantitative controls, obtained using a ribosomal RNA probe as reference (Fig. 3A), the levels of both TcAPX transcripts appeared to be similar between all T. cruzi BZS and BZR sample pairs analysed. In order to confirm this finding, real-time RT-PCR was employed to quantify the ratio between the numbers of molecules in different sample, considering the PCR cycle threshold values. The amount of TcAPX cDNA in the samples of $T$. cruzi were normalised by reference to the single copy housekeeping gene TcHGPRT. The results, shown in Fig. 3B, indicate that the numbers of copies of TcAPX were similar in all T. cruzi populations analysed, independently of the BZ-resistance phenotype.

Levels of TcAPX protein expression - Anti-rTcAPX polyclonal antibodies, produced in rabbits using GSTtagged rTcAPX protein as antigen, were employed in Western blot analyses to determine the amount of TcAPX protein expressed in populations of $T$. cruzi that were BZS or BZR. For all of the T. cruzi strains analysed, the rTcAPX antibody recognised a 33-kDa band in the West-
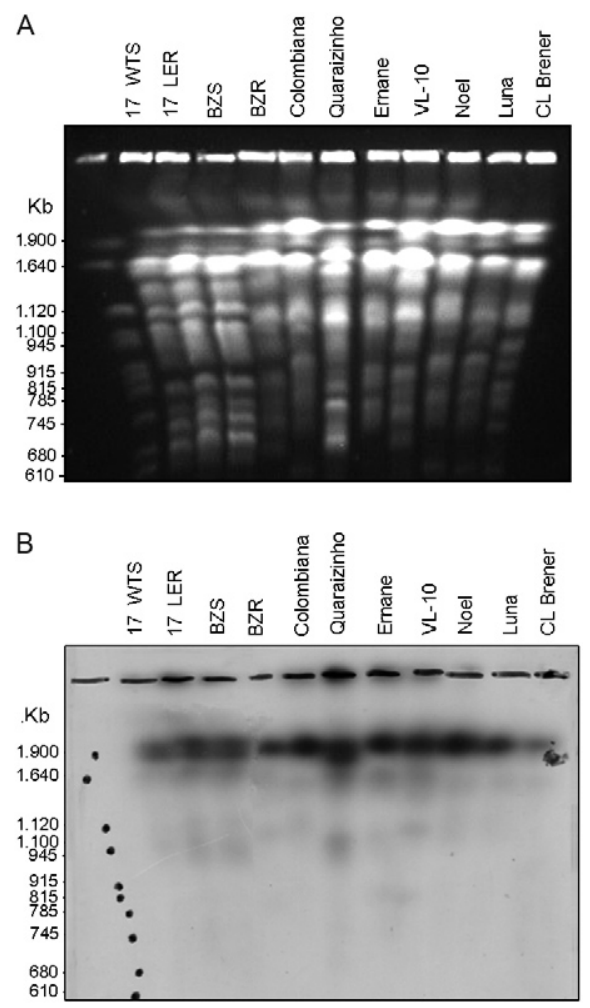

Fig. 2: chromosomal location of the Trypanosoma cruzi ascorbate peroxidase $(T c A P X)$ gene in benznidazole BZ-susceptible and BZ-resistant $T$. cruzi populations showing chromosomal bands that had been separated by pulsed-field gel electrophoresis and stained with ethidium bromide (A) and Southern blots obtained by hybridizing the chromosome bands with a ${ }^{32}$ P-labeled TcAPX-specific probe (B). Whole chromosomes from Saccharomyces cerevisiae were employed as molecular weight markers. LER: resistant-population; WTS: wild-type population. 
ern blots corresponding to the native protein (Fig. 4). In order to provide a quantitative control, the same membranes were incubated with anti-TcHSP70 polyclonal antibodies (diluted 1:10,000), since the levels of expression of this heat shock protein (HSP) were identical in all $T$. cruzi samples analysed (Murta et al. 2008). Densitometric analysis and subsequent normalisation with TcHSP70 showed that the levels of expression of the TcAPX protein in T. cruzi populations with 17 LER and BZR resistance to BZ were two and three-fold higher, respectively, than those of their counterparts (17 WTS and BZS) (Fig. 4). No differences in the levels of expression of TcAPX protein could be detected between the other strains of $T$. cruzi analysed. Additionally, when Western blot analyses the were carried out using Invitrogen (Carlsbad, CA, USA) anti-GST antibodies (diluted 1:15,000) no components of the total protein extracts from any of the T. cruzi strains were recognized (data not shown) indicating that the rTcAPX antibody was specific.

Tolerance of T. cruzi populations to hydrogen peroxide - In vitro assays (Fig. 5) revealed that the BZ-resistant $T$. cruzi populations 17 LER and BZR $\left(\mathrm{IC}_{50}\right.$ values 300 and $200 \mu \mathrm{M}$, respectively) were two-fold more tolerant of exog-

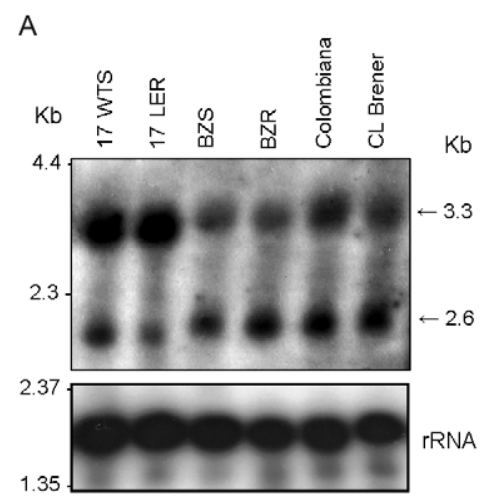

B

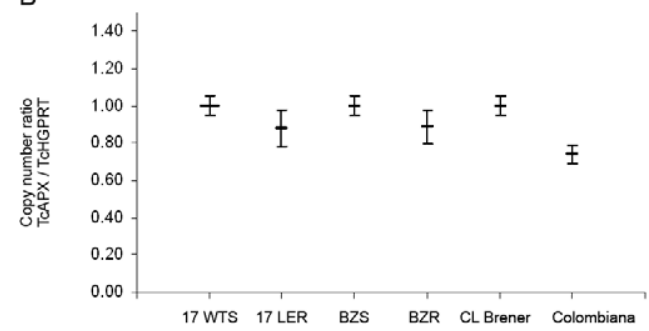

Fig. 3: levels of transcription of the Trypanosoma cruzi ascorbate peroxidase $(T c A P X)$ gene in benznidazole BZ-susceptible and BZresistant $T$. cruzi populations showing Northern blot profiles of total RNA extracts obtained using a ${ }^{32} \mathrm{P}$-labeled TcAPX- specific probe (top panel) - as quantitative control, the same membrane was subsequently exposed to a T. cruzi ribosomal RNA probe (bottom panel) (A) - and levels of TcAPX mRNA as determined quantitatively [relative to the single-copy housekeeping gene hypoxanthine-guanine phosphoribosyltransferase (TcHGPRT)] by real-time transcriptase-polymerase chain reaction (B). Mean values of the copy number ratio TcAPX/ $\mathrm{TcHGPRT} \pm$ standard deviations from three independent experiments are indicated. LER: resistant-population; WTS: wild-type population. enous hydrogen peroxide than their counterparts, 17 WTS and BZS ( $\mathrm{IC}_{50}$ values 150 and $100 \mu \mathrm{M}$, respectively).

Induction of TcAPX gene expression by hydrogen peroxide - In order to investigate the possibility that expression of TcAPX in T. cruzi is regulated by hydrogen peroxide stress, BZS and BZR populations of the protozoan were cultured in the presence of different concentrations of hydrogen peroxide. Western blot analysis of TcAPX in cells of the resistant populations 17 LER and BZR showed that levels of the protein increased in a dose-dependent manner following treatment with 100 and $200 \mu \mathrm{M}$ hydrogen peroxide (Fig. 6). However, under the assay conditions employed, oxidative stress generated by increased concentrations of hydrogen peroxide did not modulate TcAPX expression in the 17 WTS and BZS populations. Concentrations of hydrogen peroxide in excess of $400 \mu \mathrm{M}$ and prolonged periods of incubation were sub-lethal or lethal to T. cruzi parasites.

\section{DISCUSSION}

In the present study, a gene encoding APX (TcAPX) has been characterised in eleven T. cruzi strains, some of which showed resistance to BZ. TCAPX encodes a protein comprising 328 amino acids with a predicted mass of $33 \mathrm{kDa}$. Western blot analysis, using antiserum raised against this protein, confirmed the presence of the polypeptide in all of the T. cruzi strains analysed.

APX is a class I heme-containing peroxidase that catalyses the hydrogen-peroxide-dependent oxidation of ascorbate to water, although the enzyme plays no role in the detoxification of organic peroxides (Wilkinson et al. 2002). Bioinformatic analysis have revealed that full copies of TcAPX are we present in two different contigs, indicating that two complete copies of the gene (with 98\% similarity) are dispersed within the parasite genome. Karyotype analysis indicated that TcAPX was present in the 2,000-kb chromosome of all of the T. cruzi strains analysed.

Phylogenetic analysis was carried out by comparing the amino acid sequence of TcAPX with the sequences of APXs from Leishmania species and from a higher

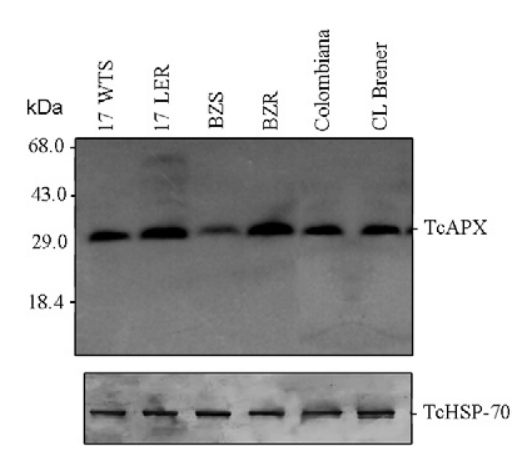

Fig. 4: levels of expression of the Trypanosoma cruzi ascorbate peroxidase (TcAPX) protein in benznidazole BZ-susceptible (BZS) and BZ-resistant (BZR) T. cruzi strains showing Western blots that had been probed with polyclonal antisera raised against the recombinant proteins TcAPX and heat shock protein of $70 \mathrm{kDa}$ (TcHSP70). LER: resistant-population; WTS: wild-type population. 
plant (A. thaliana). The results showed that $T$. cruzi APX exhibits higher levels of similarity to the enzymes from Leishmania spp (57\%) than to the APXs from A. thaliana $(25 \%)$. Analysis of the primary structure of TcAPX, together with phylogenetic considerations, suggested a common origin of the hemoperoxidases of trypanosomatids and plants, with subsequent evolutionary divergence. Supporting this hypothesis is the fact that other enzymes of this type, including a T.cruzi glutathionedependent peroxidase, show considerable similarities to those found in plants, the origins of which may be related to gene transfer events in the evolution of these organisms (Wilkinson et al. 2002). Interestingly, however, evolutionary modifications within the family Trypanosomatidae have resulted in the absence of the gene in $T$. brucei, the causative agent of African trypanosomiasis (or sleeping sickness). Elimination of this gene could be related to the environment within the host since $T$. cruzi

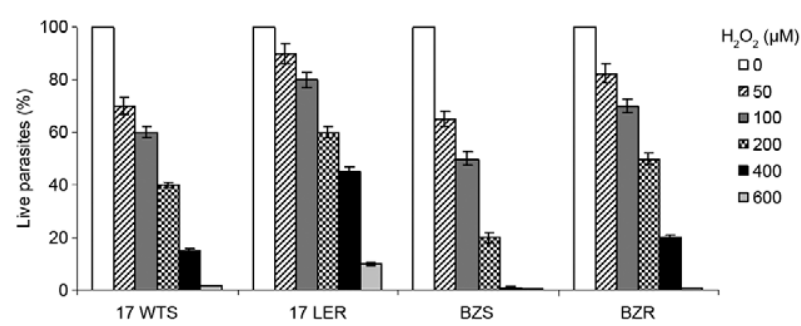

Fig. 5: in vitro tolerances of benznidazole BZ-susceptible and BZ-resistant $T$. cruzi populations to exogenous hydrogen peroxide. Parasites were cultured for three days in the presence of different concentrations of hydrogen peroxide and the percentages of live parasites determined using a model Z1 Coulter Counter. Mean values \pm standard deviations from three independent experiments in triplicate are indicated. LER: resistant-population; WTS: wild-type population. and Leishmania spp. are intracellular parasites while the African trypanosomes are extracellular. It may be that an ascorbate-dependent antioxidant defence during infection is more crucial for T. cruzi and Leishmania spp than for T. brucei (Wilkinson et al. 2005).

The unique antioxidant defence system in trypanosomatids is based on the low-molecular-weight thiol $\mathrm{T}(\mathrm{SH})_{2}$, which maintains the intracellular environment in a reduced state essentially by the action of $\mathrm{T}(\mathrm{SH})_{2}$ reductase. Further pathways, which are coupled with the $\mathrm{T}(\mathrm{SH})_{2}$ cycle and catalysed by tryparedoxin peroxidase and APX, are responsible for the subsequent detoxification of hydrogen peroxide to water. Previous studies by our group have shown that the levels of expression of cytosolic and mitochondrial tryparedoxin peroxidases are increased in populations of $T$. cruzi with in vitro induced resistance to BZ (Nogueira et al. 2009). The present study has demonstrated that APX expression is increased in $T$. cruzi populations with in vivo selected (BZR) and in vitro induced resistance to BZ (17 LER) in comparison with their respective counterparts BZS and 17 WTS.

The trypanocidal effect of BZ depends on the reduction of its nitro group (Docampo \& Moreno 1984). A oneelectron reduction leads to nitro-anion radical formation and its re-oxidation in the presence of oxygen leads to the formation of non-toxic BZ and ROS (Moreno et al. 1982, Morello 1988). Although this detoxifies the drug, it also generates toxic superoxide anion radicals. The enzyme iron-superoxide dismutase (TcFeSOD) removes this anion, leading to the production of hydrogen peroxide that is then converted to water molecules by tryparedoxin peroxidase and APX. Interestingly, our group has shown that these three enzymes are over-expressed in the population of T. cruzi with in vitro induced resistance to BZ (Nogueira et al. 2006, 2009). An alternative hypothesis that could correlate the overexpression
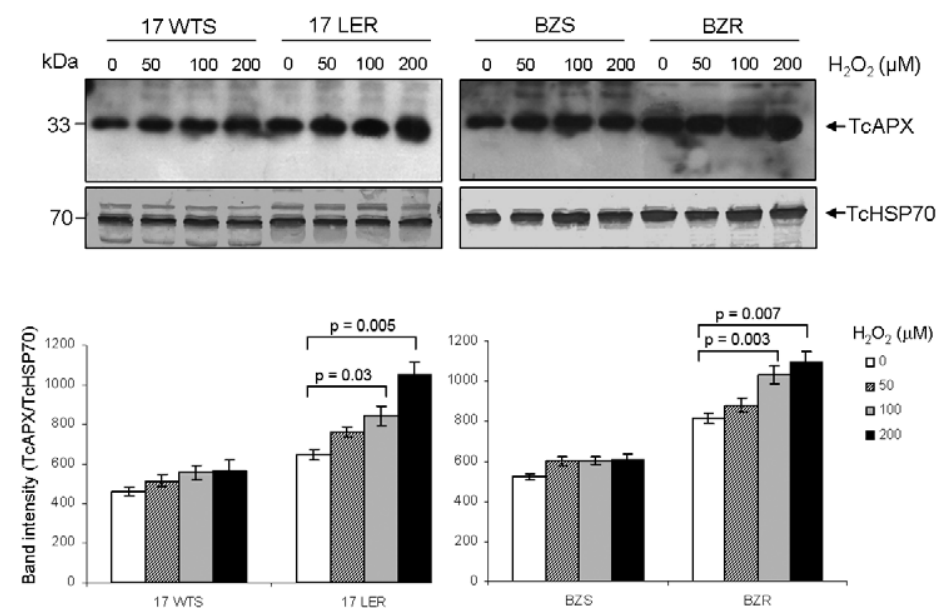

Fig. 6: Western blot analysis of levels of Trypanosoma cruzi ascorbate peroxidase (TcAPX) protein in benznidazole BZ-susceptible and BZresistant $T$. cruzi populations after exposure to exogenous hydrogen peroxide. Parasites were incubated in the presence of $0,50,100$ or $200 \mu \mathrm{M}$ hydrogen peroxide at room temperature for $1 \mathrm{~h}$ and protein extracts $(20 \mu \mathrm{g})$ were submitted to Western blot analysis using anti-TcAPX recombinant protein and anti-heat shock protein (rTcHSP70) antibodies. Quantification of bands was done by densitometric scanning (ImageMaster VDS software) and data were statistically analyzed by the Student's $t$ test. The data represent mean \pm standard deviations from two independent experiments. A p value of less than 0.05 was considered significant. LER: resistant-population; WTS: wild-type population. 
of these enzymes with $T$. cruzi resistance to BZ could be related with the NADH-fumarate reductase enzyme. It has been shown that the incomplete inhibition of NADH-fumarate reductase by BZ might transfer electrons to stronger oxidants, as molecular oxygen, producing superoxide anions (Turrens et al. 1996).

The mechanism of drug resistance, such as that to $\mathrm{BZ}$, is often complex and multi-factorial, involving different pathways. Recently, it has been described in the literature that the key step involved in the BZ activation is catalysed by a type I NTR (Wilkinson et al. 2008). Deletion of copies of genes TcOYE and NTR encoding two different NTRs, was associated with resistance of $T$. cruzi to BZ in vitro (Murta et al. 2006, Wilkinson et al. 2008). In addition, our present and previous data show that the resistant parasites also overexpress enzymes involved in the antioxidant defence (TcFeSOD, tryparedoxin peroxidase and APX), thus detoxifying the parasite and making it BZ-resistant.

It was of interest to determine whether the presence of exogenous hydrogen peroxide would affect the levels of TcAPX protein in BZS and BZR T. cruzi populations in a differential manner. The results obtained show that the expression of TcAPX protein is increased by treatment with exogenous hydrogen peroxide, indicating that TcAPX expression can be induced by oxidative stress. However, under the assay conditions employed, such modulation of APX expression was observed in the resistant parasites 17 LER and BZR, but not in their counterparts 17 WTS and BZS. These findings suggest that resistant parasites may use APX to overcome oxidative stress, a hypothesis that is in agreement with the present results demonstrating that levels of expression of TcAPX are higher in BZ-resistant T. cruzi populations. In this context, it has previously been observed that, following exposure to exogenous hydrogen peroxide, populations of $T$. cruzi that over-expressed APX showed a two-fold increase in resistance to BZ in comparison with the controls (Wilkinson et al. 2002).

Interestingly, L. major and Glycine max (soybean) cells also over-express APX in the presence of hydrogen peroxide. Thus, Dolai et al. (2008) demonstrated that the transcription level of LmAPX in L. major was six-fold higher in parasites that had been cultured in the presence of hydrogen peroxide compared with the untreated control. Moreover, the parasites that overexpressed LmAPX presented decreased levels of ROS in the mitochondria and showed a 2.5 -fold increase in resistance to exogenous hydrogen peroxide. Increased transcription of APX has also been observed in cultured soybean cells that had been treated with exogenous hydrogen peroxide (Lee et al. 1999).

In the present study, two TcAPX transcripts, one of $2.6 \mathrm{~kb}$ and another of $3.3 \mathrm{~kb}$, were detected in all populations of $T$. cruzi analysed. These two transcripts could be associated with different maturation levels of the mRNA, differences in the size of the 5' and $3^{\prime}$ untranslated regions or differences in the length of the poly-A tail of the mRNA (Teixeira \& Da Rocha 2003). The levels of TcAPX mRNA, as determined by Northern blot and real-time RT-PCR analyses, were found to be similar in all T. cruzi populations, irrespective of the drug resistance phenotype. However, the results from Western blot analyses revealed that the expression levels of TcAPX protein were two and three-fold higher in T. cruzi populations with in vitro induced and in vivo selected resistance to $\mathrm{BZ}$, respectively, in comparison with their susceptible counterparts. Since gene expression in trypanosomatids is regulated mainly at the posttranscription level (Vanhame \& Pays 1995), our results suggest that the higher levels of TcAPX protein detected in the resistant parasites are related to the superior stability of mRNA and/or the greater efficiency of protein translation in comparison with susceptible populations.

Cells can develop resistance to oxidative stress by increasing the expression of genes that encode enzymes involved in antioxidant defence and repair systems (Steenkamp 2002, Finzi et al. 2004). Consideration of the results from our present and previous studies (Nogueira et al. 2006, 2009) leads to the conclusion that cells of the T. cruzi population with in vitro induced resistance to BZ are protected against oxidative stress by a mechanism involving over-expression of tryparedoxin peroxidase, APX and other enzymes associated with antioxidant defence, including iron superoxide dismutase. The T. cruzi population with in vivo selected resistance to $\mathrm{BZ}$ also presented higher expression level of TcAPX protein, thus supporting the hypothesis that the antioxidant defence system acts in concert in contributing to $\mathrm{BZ}$ resistance in the parasite. In addition, we have shown that BZ-resistant parasites are more tolerant of exogenous hydrogen peroxide than their susceptible counterparts and can modulate TcAPX expression in response to cellular levels of the peroxide, thus protecting themselves against lethal damage. It is concluded that the absence of APX in mammals and its importance in the antioxidant defence system of trypanosomatids make this enzyme a rational target for chemotherapy against Chagas disease.

\section{REFERENCES}

Boveris A, Sies H, Martino EE, Docampo R, Turrens JF, Stoppani AO 1980. Deficient metabolic utilization of hydrogen peroxide in Trypanosoma cruzi. Biochem J 188: 643-648.

Carnieri EG, Moreno SN, Docampo R 1993. Trypanothione-dependent peroxide metabolism in Trypanosoma cruzi different stages. Mol Biochem Parasitol 61: 79-86.

CDC - Centers for Disease Control and Prevention 2007. American trypanosomiasis (also known as Chagas Disease). Available from: cdc.gov/parasites/chagas/.

Clark D, Albrecht M, Arevalo J 1994. Ascorbate variations and dehydroascorbate reductase activity in Trypanosoma cruzi epimastigotes and trypomastigotes. Mol Biochem Parasitol 66: 43-45.

Docampo R 1990. Sensitivity of parasites to free radical damage by antiparasitic drugs. Chem Biol Interact 73: 1-27.

Docampo R, de Boiso JF, Boveris A, Stoppani AO 1976. Localization of peroxidase activity in Trypanosoma cruzi microbodies. Experientia 32: 972-975.

Docampo R, Moreno SN 1984. Free radical metabolites in the mode of action of chemotherapeutic agents and phagocytic cells on Trypanosoma cruzi. Rev Infect Dis 6: 223-238.

Dolai S, Yadav RK, Pal S, Adak S 2008. Leishmania major ascorbate peroxidase overexpression protects cells against reactive 
oxygen species-mediated cardiolipin oxidation. Free Radic Biol Med 45: 1520-1529.

Efron B, Halloran E, Holmes S 1996. Bootstrap confidence levels for phylogenetic trees. Proc Natl Acad Sci USA 93: 13429-13434.

El-Sayed NM, Myler PJ, Blandin G, Berriman M, Crabtree J, Aggarwal G, Caler E, Renauld H, Worthey EA, Hertz-Fowler C, Ghedin E, Peacock C, Bartholomeu DC, Haas BJ, Tran AN, Wortman JR, Alsmark UCM, Angiuoli S, Anupama A, Badger J, Bringaud F, Cadag E, Carlton JM, Cerqueira GC, Creasy T, Delcher AL, Djikeng A, Embley TM, Hauser C, Ivens AC, Kummerfeld SK, Pereira-Leal JB, Nilsson D, Peterson J, Salzberg SL, Shallom J, Silva JC, Sundaram J, Westenberger S, White O, Melville SE, Donelson JE, Andersson B, Stuart KD, Hall N 2005. Comparative genomics of trypanosomatid parasitic protozoa. Science 309: 404-409.

Filardi LS, Brener Z 1987. Susceptibility and natural resistance of Trypanosoma cruzi strains to drugs used clinically in Chagas disease. Trans R Trop Med Hyg 81: 755-759.

Finzi JK, Chiavegatto CW, Corat KF, Lopez JA, Cabrera OG, Mielniczki-Pereira AA, Colli W, Alves MJ, Gadelha FR 2004. Trypanosoma cruzi response to the oxidative stress generated by hydrogen peroxide. Mol Biochem Parasitol 133: 37-43.

Flohé L, Hecht HJ, Steinert P 1999. Glutathione and trypanothione in parasitic hydroperoxide metabolism. Free Radic Biol Med 27: 966-984.

Garg N, Popov VL, Papaconstantinou J 2003. Profiling gene transcription reveals a deficiency of mitochondrial oxidative phosphorylation in Trypanosoma cruzi-infected murine hearts: implications in chagasic myocarditis development. Biochim Biophys Acta 1638: 106-120.

Irigoín F 2008. Insights into the redox biology of Trypanosoma cruzi: trypanothione metabolism and oxidant detoxification. Free Radic Biol Med 45: 733-742.

Krauth-Siegel RL, Meiering SK, Schmidt H 2003. The parasite-specific trypanothione metabolism of Trypanosoma and Leishmania. Biol Chem 384: 539-549.

Kumar S, Tamura K, Nei M 2004. MEGA3: integrated software for molecular evolutionary genetics analysis and sequence alignment. Brief Bioinform 5: 150-163.

Lee SC, Kang BG, Oh SE 1999. Induction of ascorbate peroxidase by ethylene and hydrogen peroxide during growth of culture soybean cells. Mol Cells 9:166-171.

Massad E 2008. The elimination of Chagas disease from Brazil. Epidemiol Infect 136: 1153-1164.

Maya JD, Repetto Y, Agosín M, Ojeda JM, Tellez R, Gaule C, Morello A 1997. Effects of nifurtimox and benznidazole upon glutathione and trypanothione in epimastigote, trypomastigote and amastigote forms of Trypanosoma cruzi. Mol Biochem Parasitol 86: 101-106.

Morello A 1988. The biochemistry of the mode of action of drugs and the detoxication mechanisms in Trypanosoma cruzi. Comp Biochem Physiol C 90: 1-12.

Moreno SN, Docampo R, Mason RP, Leon W, Stoppani AO 1982. Different behaviours of benznidazole as free radical generator with mammalian and Trypanosoma cruzi microsomal preparations. Arch Biochem Biophys 218: 585-591.

Murta SM, Krieger MA, Montenegro LR, Campos FF, Probst CM, Avila AR, Muto NH, de Oliveira RC, Nunes LR, Nirdé P, BrunaRomero O, Goldenberg S, Romanha AJ 2006. Deletion of copies of the gene encoding old yellow enzyme (TcOYE), a $\mathrm{NAD}(\mathrm{P}) \mathrm{H}$ flavin oxidoreductase, associates with in vitro-induced benznidazole resistance in Trypanosoma cruzi. Mol Biochem Parasitol 146: 151-162.
Murta SM, Nogueira FB, Dos Santos PF, Campos FM, Volpe C, Liarte DB, Nirde P, Probst CM, Krieger MA, Goldenberg S, Romanha AJ 2008. Differential gene expression in Trypanosoma cruzi populations susceptible and resistant to benznidazole. Acta Trop 107: 59-65.

Murta SMF, Gazzinelli RT, Brener Z, Romanha AJ 1998. Molecular characterization of susceptible and naturally resistant strains of Trypanosoma cruzi to benznidazole and nifurtimox. Mol Biol Parasitol 93: 203-214.

Murta SMF, Romanha AJ 1998. In vivo selection of a population of Trypanosoma cruzi and clones resistant to benznidazole. Parasitology 116: 165-171.

Nirdé P, Larroque C, Barnabé C 1995. Drug-resistant epimastigotes of Trypanosoma cruzi and persistence of this phenotype after differentiation into amastigotes. Med Sci 318: 1239-1244.

Nogoceke E, Gommel DU, Kiess M, Kalisz HM, Flohé L 1997. A unique cascade of oxidoreductases catalyses trypanothionemediated peroxide metabolism in Crithidia fasciculata. Biol Chem 378: 827-836.

Nogueira FB, Krieger MA, Nirdé P, Goldenberg S, Romanha AJ, Murta SM 2006. Increased expression of iron-containing superoxide dismutase-A (TcFeSOD-A) enzyme in Trypanosoma cruzi population with in vitro-induced resistance to benznidazole. Acta Trop 100: 119-132.

Nogueira FB, Ruiz JC, Romanha AJ, Murta SMF 2009. Molecular characterization of cytosolic and mitochondrial tryparedoxin peroxidase in Trypanosoma cruzi populations susceptible and resistant to benznidazole. Parasitol Res 104: 835-844.

Piñeyro MD, Pizarro JC, Lema F, Pritsch O, Cayota A, Bentley GA, Robello C 2005. Crystal structure of the tryparedoxin peroxidase from the human parasite Trypanosoma cruzi. J Struct Biol 150: $11-22$

Raven EL 2003. Understanding functional diversity and substrate specificity in haem peroxidases: what can we learn from ascorbate peroxidase? Nat Prod Rep 20: 367-381.

Steenkamp DJ 2002. Trypanosomal antioxidants and emergenging aspects of redox regulation in the trypanosomatids. Antioxid Redox Signal 4: 105-121.

Stuart K, Brun R, Croft S, Fairlamb A, Gürtler RE, McKerrow J, Reed S, Tarleton R 2008. Kinetoplastids: related protozoan pathogens, different diseases. J Clin Invest 118: 1301-1310.

Teixeira SM, Da Rocha WD 2003. Control of gene expression and genetic manipulation in the Trypanosomatidae. Genet Mol Res 2: $148-158$.

Thompson JD, Gibson TJ, Plewniak F, Jeanmougin F, Higgins DG 1997. The CLUSTALX windows interface: flexible strategies for multiple sequence alignment aided by quality analysis tools. $\mathrm{Nucl}$ Acids Res 25: 4876-4882.

Toledo MJ, Bahia MT, Veloso VM, Carneiro CM, Machado-Coelho GL, Alves CF, Martins HR, Cruz RE, Tafuri WL, Lana M 2004. Effects of specific treatment on parasitological and histopathological parameters in mice infected with different Trypanosoma cruzi clonal genotypes. J Antimicrob Chemother 53: 1045-1053.

Turrens JF 2004. Oxidative stress and antioxidant defenses: a target for the treatment of diseases caused by parasitic protozoa. Mol Asp Med 25: 211-220.

Turrens JF, Watts BP Jr, Zhong L, Docampo R 1996. Inhibition of Trypanosoma cruzi and T. brucei NADH fumarate reductase by benznidazole anthelmintic imidazole derivates. Mol Biochem Parasitol 82: 125-129.

Urbina JA, Docampo R 2003. Specific chemotherapy of Chagas disease: controversies and advances. Trends Parasitol 19: 495-501. 
Vanhame L, Pays E 1995. Control of gene expression in Trypanosomes. Microbiol Rev 59: 223-240.

Wilkinson SR, Obado SO, Mauricio IL, Kelly JM 2002. Trypanosoma cruzi expresses a plant-like ascorbate-dependent hemoperoxidase localized to the endoplasmic reticulum. Proc Natl Acad Sci USA 99: 13453-13458.

Wilkinson SR, Prathalingam SR, Taylor MC, Horn D, Kelly JM 2005. Vitamin $\mathrm{C}$ biosynthesis in trypanosomes: a role for the glycosome. Proc Natl Acad Sci USA 102: 11645-11650.
Wilkinson SR, Taylor MC, Horn D, Kelly JM, Cheeseman I 2008. A mechanism for cross-resistance to nifurtimox and benznidazole in trypanosomes. Proc Natl Acad Sci USA 105: 5022-5027.

Zingales B, Andrade SG, Briones MRS, Campbell DA, Chiari E, Fernandes O, Guhl F, Lages-Silva E, Macedo AM, Machado CR, Miles MA, Romanha AJ, Sturm NR, Tibayrenc M, Schijman AG 2009. A new consensus for Trypanosoma cruzi intraspecific nomenclature: second revision meeting recommends $\mathrm{TcI}$ to $\mathrm{TcVI}$. Mem Inst Oswaldo Cruz 104: 1051-1054. 


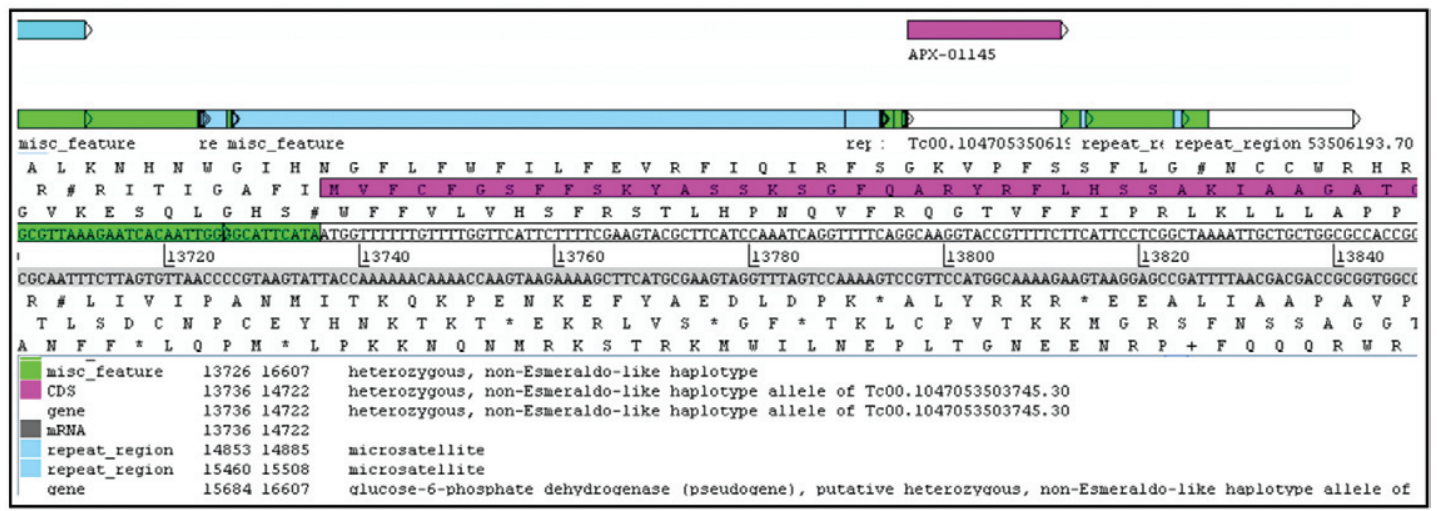

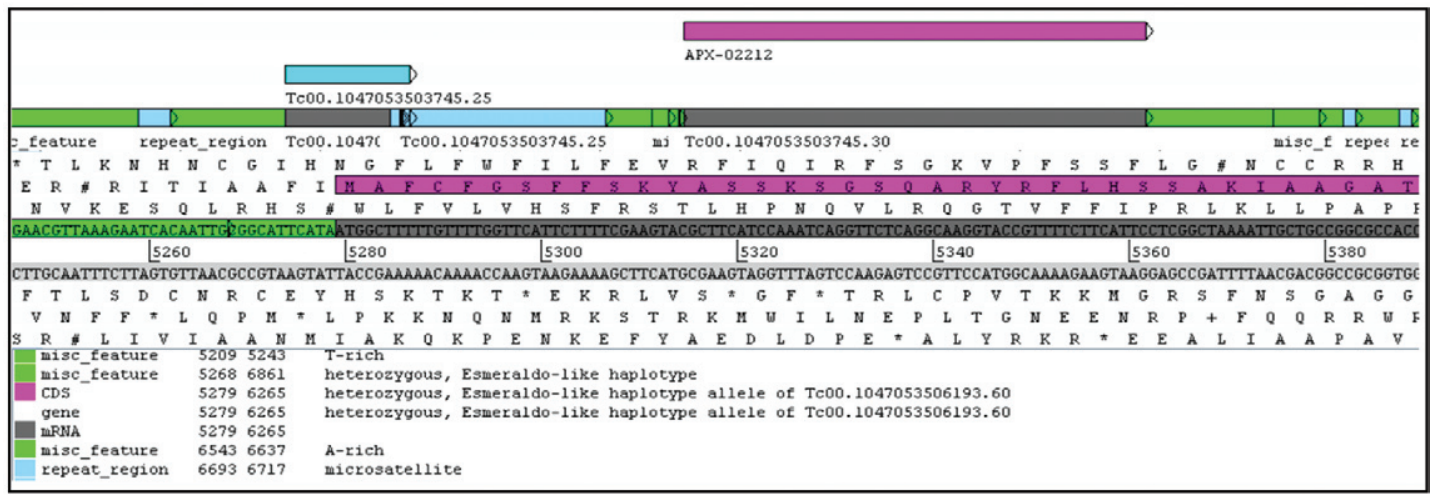

Annotation and graphical output of the Trypanopoma cruzi contigs AAHK01001145 (A) and AAHK01002212 (B) containing copies of the T. cruzi ascorbate peroxidase (TcAPX) gene using ARTEMIS software. The TcAPX gene is indicated in pink colour in each contig.

\begin{tabular}{|c|c|}
\hline APX-01145 & MVF CF GSFF SKYASSKSGF QARYRFLHS \\
\hline \multicolumn{2}{|r|}{$\ldots \ldots \ldots \ldots$ s..... } \\
\hline \multicolumn{2}{|l|}{ Clustal Consensus } \\
\hline & $\begin{array}{c}110 \\
\ldots 1 \ldots 1 \ldots 1 \ldots 1 \ldots 1 \\
0\end{array}$ \\
\hline APX-01145 & RKKDGSPHSASIRF HPECSYAGKKGLD \\
\hline APX-02212 & $\cdots \ldots \ldots$ \\
\hline \multirow[t]{3}{*}{ clustal Consensus } & 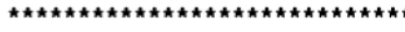 \\
\hline & 210 \\
\hline & $\ldots-1 \ldots|\ldots| \ldots|\ldots| \ldots$ \\
\hline APX-01145 & SRLGFNDEE TVAL I GAHT CGECHLENT \\
\hline APX-02212 & $\ldots \cdots \cdots \cdots \cdots \cdots \cdots \cdots \cdots$ \\
\hline \multirow[t]{2}{*}{ Clustal Consensus } & 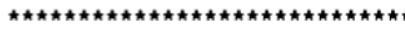 \\
\hline & $\begin{array}{c}{ }^{310} \\
\ldots 1 \ldots 1 \ldots 1 \ldots 1 \ldots 1 \ldots\end{array}$ \\
\hline APX-01145 & FCKAF SKAYQKLLEVGTTMLKSLPAES \\
\hline APX-02212 & $\ldots \ldots \ldots \ldots \ldots \ldots \ldots \ldots$ \\
\hline clustal Con & 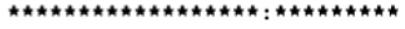 \\
\hline
\end{tabular}

Global sequence alignment of amino acid sequences of the Trypanosoma cruzi ascorbate peroxidase (TcAPX) gene (GenBank accessions CAD30023 and XP 804882) present in the contigs AAHK01001145 (APX-01145) and AAHK01002212 (APX-02212), respectively. The sequences were aligned using CLUSTALW Windows interface. 